we learn in some detail, the US licensing process allowed groups to quibble for more than twenty years about the solidity of bridges, and the miniscule rise in ocean temperature caused by the plant; at no time in the process were people able to debate in a meaningful way the overarching issue of nuclear power, or the political and philosophical underpinnings of the participants that led them to such divergent views. Woefully, it seems, our society has yet to learn the process or vocabulary for such debates. Hence, technological questions of major importance to us all seem to get decided, if at all, in a shamefully ad hoc, de facto way.

If there is a flaw to Bedford's careful and clear case study of the Seabrook plant it is that he does not provide the reader with quite enough context fully to appreciate the circumstances. Most notable, of course, is the parallel story of Seabrook's sister reactor, the Shoreham plant in Long Island, New York. The unopened Shoreham plant has now been sold to New York state for one dollar, with the state assuming closing costs and vowing that the plant will never generate electricity. The divergent ends reached in these two cases make for a fascinating comparison: why did one constructed plant receive its licence whereas the other was effectively blocked by opponents? Similarly, Bedford could have offered more general background of the status of nuclear power in the United States. On economics issues, for example, he admirably explains the complexity of the financing as Seabrook's small public utility went ever more deeply into debt. But Bedford might have offered a bit of context here as well: all of the several lingering nuclear plants under construction during this period faced skyrocketing costs. Such a comparative perspective might have reminded us of the broader world in which Seabrook operated.

But this was not Bedford's aim. Rather he sought to do a close portrait of one dinosaur, and as such his work succeeds splendidly. In the end we learn much about how not to conduct public debate about technology. But we also learn how so many poor decisions could have been piled on top of each other to allow such an ill-advised project to proceed. The reasons are complex, but they are also caricatured beautifully by an administrator early on in Bedford's book advancing his so-called dinosaur theory to explain the Seabrook phenomenon. As Bedford writes, the administrator asks, "If you have a dinosaur in your backyard, you have to keep feeding it, because what can you do with a dead dinosaur?" We have only to watch the nearby Shoreham plant, I suppose, for answers.

Seth Shulman is at 28 Bates Road, Watertown, Massachusetts 02172, USA.

\section{Indigestible science?}

Ken Ducatel

The New Technology. By Dimitris N. Chorafas. Sigma: 1990 (marketed by John Wiley and Sons Ltd). Pp. 410. $£ 14.95$.

THERE have been many recent books which have brought advances in science to the attention of a wider audience. Current media interest in issues such as the new physics, chaos theory, cosmology, genetics and artificial intelligence undoubtedly originates in popular science books written by specialists in these fields.

What we still lack is an accessible, but properly documented, overview of the implications of advances in science and technology for medium to long-term industrial strategy. With the widespread recognition of the salience of new technologies in competitive performance such a book has a guaranteed market amongst industrialists and policy makers. Yet it does not exist. It seems that the main reason why this book has still to be written is that it would be incredibly hard to do well. Not only would it have to summarize the technologies quickly, simply and accurately, it is also notoriously difficult to forecast technological progress accurately.

Good authorial style would be crucial. It takes a certain skill to make science digestible to a general audience whilst not being howled down by the experts in the field. It would also be necessary for instance to observe scientific rules about the presentation of information, such as adequate attribution and accuracy in the use of data, as well as extensive use of visual devices and conceptual models to convey the substance of the sometimes elegant, sometimes complex subject matter.

We may also ask, how confident an author can be in identifying the precise areas of technical advance which will be economically important in the next ten to twenty years. It is hard enough to forecast with precision how fast single new technologies are gaining acceptance in the commercial world. When it comes to describing the interaction between economic forces and an array of new technologies, accurate forecasts are out of the question. The only solution to the forecasting problem is a powerful explanatory model of the process by which new systems of technology are introduced into society. In the past there have been periods of great economic change and crisis as an existing system of technology burns out and is shaken out of the economy and the new technological system is installed. We have been undergoing just such a period of shift in the "technoeconomic paradigm" since the early 1970 s. The rate of adoption of new technologies and therefore their significance to industrialists and policy makers will depend upon their relation to the point in the cycle of these paradigms which we have reached. By using a powerful concept such as the techno-economic paradigm, order can be imposed on the book's analysis of the economic and social consequences of competing science and technology developments.

A full plan for the book on future technologies for concerned managers cannot be worked out here, but its fundamental features are given above. It would have to be written in an accessible but reflective style, so that justice is done to scientific knowledge. It would also need a strong conceptual core, to give the reader an orientation to the overall streams and currents of technological change. Unfortunately, although apparently recognizing that the niche exists, Dimitris Chorafas has produced a book which fails to meet these criteria. I will restrict my discussion to three basic problems: style, attribution and structure.

First, the writing style of the author is idiosyncratic to say the least. In what is apparently an attempt to write in a downto-earth style, he uses short choppy sentences, sometimes dispensing altogether with the verb in the sentence. There are instances where the author's use of English is so strange as to make the text incoherent and in some cases laughable. A howler such as "winds of change can be seen" (page 15) is merely an example. The general effect is of a rather rushed translation by someone who is not a native English speaker. Second, the book lacks any systematic reference system; despite the author's habit of copious name dropping, few references are listed. The lack of attribution in popular nonfiction is justified on the grounds that full referencing obstructs the flow of argument. In this book it is symptomatic of a general neglect of appropriate standards in the reporting of scientific knowledge. Readers not familiar with an area who want to follow up points which are being made in the text will find this impossible, as the book lacks even a guide to further reading. Graphs and tables suffer a similar fate with, in most cases, no attributed source and in some cases no scale on the axes.

Third, the book lacks a central conceptual approach, beyond the theme that 'science is discovery is progress'. As a result the discussion of the different technological developments is without focus. The book styles itself as a survival guide for the $1990 \mathrm{~s}$, which would imply that it should be used as a resource to gain access to some of the leading-edge technological developments. In the absence both of a systematizing conceptual model of how 
technologies move into the economic sphere and without an adequate referencing system it is hard to see how the book can be termed a guide in any sense of the word. It cannot be used to gain access to a wider world of knowledge about specific technologies, as in a hitch-hikers guide to new technology. Nor can it be used as a knowledge development tool in its own right, in the sense of a do-it-yourself action plan to new technology.

Somewhere in this volume is an interesting book trying to get out. The hyped-up, chopped-down delivery style appropriate to managerial seminars does not work in book format. Although the author may have a grasp of a wide range of recent scientific developments, his ideas about what these mean for the future are not effectively conveyed here. Perhaps the management seminars are better value. A treatment of these issues aimed at policy makers would be very appropriate during the current period of technological restructuring. It is a shame, but this is not the book.

Ken Ducatel is in the Department of Science and Technology Policy, University of Manchester, Oxford Road, Manchester M13 9PL, UK.

\section{Hidden message}

\section{John Galloway}

\section{Opportunities in Blology. National Academy Press: 1990. Pp. 448. \$51.}

There is a tale - I hope it is not apocryphal - that Sir Lawrence Bragg, asked by the $B B C$ to take part in a radio programme, refused - on the grounds that he did not think the country could afford to have a significant part of its scientific manpower out of action for an afternoon.

No such anxiety appears to have assailed the compilers of Opportunities in Biology. The book was put together by a committee of 20 of the most successful biologists in the United States, including luminaries such as Maxwell Cowan, Leroy Hood and Eric Kandel. By way of explanation, the preface says "no single individual can hope to grasp all the new activities and opportunities (of biology)". Nor could even 20 apparently, who were aided and abetted by a National Research Council staff of seven, eleven expert panels with at least six members each, a Board on Biology, a Commission on life sciences and 94 other contributors and reviewers.

What was it Horace said about the mountains labouring? Here we have not merely any old mountains but the Olympian peaks themselves, a couple of hundred of America's finest. Horace's mountains brought forth a mouse. What has the National Research Council been delivered of? The answer is not little, but is, I am sorry to say, of little value.

Apart from its subject, you judge a book by the quality of its language. That this is a book about biology, about ideas and methods that we can confidently expect to be unfamiliar to many of those at whom it is aimed - administrators and policy makers, for example - makes the proper use of language essential. And in its language, Opportunities in Biology leaves pretty much everything to be desired. It is remarkably sloppily written - it is not precise, economical, vivid, concrete and straightforward; it does not give sufficient apt detail to support the points it wishes to make; numbers are prominent only by their scarcity. The writers have included some graphic illustrations but appear to have chosen them at random without a decided or consistent purpose.

Let me give one or two examples of language used sloppily or wrongly - a few among many:

The word environment means surroundings. It does not need the adjective surrounding to precede it.

Epstein Barr virus (EBV) does not "carry" cancer. The virus is probably one of a chain of causes leading to Burkitt's lymphoma or nasopharyngeal cancer. (It is likely that EBV infects 90 per cent or more of the world's population but the cancers in which it is implicated occur in very few areas of the world.)

On page 43 , we are told that the largest single DNA that has been sequenced is the genome of EBV with 172,000 base pairs; and yet on page 46 that the genomes of organisms range in size from 750,000 to 3 billion base pairs. Whether or not a virus is an organism depends on your view point. But to read those two statements three pages apart without a word of explanation or qualification is simply unsettling. Incidentally, the longest single piece of DNA sequenced is now that of cytomegalovirus with 230,000 base pairs. This sequence, completed last year at the Laboratory of Molecular Biology in Cambridge, is only 30 per cent longer than that of EBV. This is worth mentioning because it suggests things are progressing relatively slowly in terms of sequencing complete DNAs. The optimistic note struck in Opportunities in Biology in writing about sequencing the human genome might have been tempered by this fact.

That the book is slightly out of date in respect of the cytomegalovirus genome is probably not very important. But it is out of date in more significant ways. Arguing for more research funding on the grounds that the United States is slipping against other countries in the quality of its biological research, figures of the number of US papers in the top 10 per cent worldwide are used. But the best that can be done apparently is to use data comparing 1973 with 1980. Data one to two decades old in a book like this are not good enough.

Picking up on Sir Lawrence's view point, I could not help irreverently wondering if one reason for the worsening performance of the United States is the extent to which its scientists are involved in exercises like this one.

Actually, I was almost more concerned with the quantity of language in the book than its quality. A large proportion of it seemed superfluous. And indeed genomes seem to offer a good way of illustrating the fault. It is usual to offer language as an analogy for the information contained in DNA. In viruses all the DNA is involved in the genetic message which is precise and compressed. On the other hand, in the human genome, 97 per cent of the DNA seems to have no purpose. The genetic messages are contained in about 3 per cent of the DNA. I could not help feeling that human DNA provides a useful analogy for language as it is used here. The messages in Opportunities in Biology are contained in a small fraction of the total words (the rest just has to be ploughed through).

The book also seems curiously muddled, both in small and large ways. The executive summary tells us of some of what biology has achieved by way of understanding. It then tells us "it is ironic that a time so filled with great opportunity should also be a time when a major fraction of the diversity of life on Earth is in danger of extinction". It is not ironic. The two facts are tightly tied to each other. The main problem the Earth faces is overpopulation by people and over-use of resources by a proportion of them, the end product of the "successful" application of scientific knowledge in the form of agriculture and medicine, for instance. I could not find a section about overpopulation, nor does it have an entry in the index. Where it might have been is the word ostrich - that does seem ironic.

What is strange about the flaws in the book is that 20 years ago the same exercise was undertaken in a volume called Biology and the Future of Man edited by Philip Handler, president of the National Academy of Sciences. It was very much better written and better at explaining some of the fundamental science. And it did conclude that population was the major problem for the immediate future. The earlier book was published just before two momentous pieces of biology - the discovery of a way of making monoclonal antibodies and the development of the technology for sequencing DNA which between them changed the face of biology almost beyond recognition. I would have thought that fact alone would have caused the writers of the present book to remind its readers that predicting what will happen is a somewhat uncertain exercise in science as elsewhere. 